\title{
AMITRIPTYLINE (ELAVIIL) \\ A SEDATING ANTIDEPRESSANT WITH PRESSOR ACTIVITY \\ FOR PREOPERATIVE MEDICATION
}

\section{Paud $\mathbb{R}$ Levesque, M $\mathbb{D}$, Ogden $\mathbb{R}$ Lindsley, Ph D, and Benjamin E Etsten, m D}

A mitriptyline HYdRochloride (Elavil), a dibenzo-cyclo-heptadiene denvative is an antidepressant with a tranquillizing influence upon the central nervous system The drug has anthistaminic, anticonvulsive, and mild anticholinergic properties, ${ }^{10}$ and it has no apparent influence upon the brain serotonin content ${ }^{1-8} \quad 10 \quad 14-17$

In view of these effects, amitriptyline was evaluated as a premedicant for surgical patients prior to anaesthesia, to allay apprehension without causing undesirable side-effects

\section{Methon}

A total of 40 surgical patients, from 21 to 72 yeats of age, without apparent cardiovascular, respiratory, or neurological disease, was divided into three groups

Group I Eighteen patients were monitored with the Free-Operant Behaviour Technique before, during, and after the administration of amitriptyline (033 $\mathrm{mg} / \mathrm{kg}$ ) intravenously

Group II Eighteen patients were monitored with the Free-Operant Behaviour Technique before, during, and after the administration of halothane anaesthesia, nine of these patients were not premedicated, nine received amitriptyline (033 $\mathrm{mg} / \mathrm{kg}$ ) intravenously before anaesthesia

Group III Eleven patients had the arterial blood pressure and heart rate continuously monitored before and after the administration of amitriptyline (0.33 $\mathrm{mg} / \mathrm{kg}$ intravenously

Free Operant Behaviour-Defintion The term "operant" indicates that a subject operates a lever, switch, or similar device and is promptly "rewarded" or "reinforced" by the presentation of a rewarding or the withdrawal of an aversive event The rate of occurrence of the response is the primary datum (Fig 1 )

By means of an audiometer, a high-pitched, loud, and intermittent tone (aversive event) is produced and transmitted to the patient via earphones "The patient can decrease or eliminate the sound (reward, remforcement) by repeatedly closing thumb and finger electrical contacts on a rubber glove These contacts are wired to the sound apparatus and by means of a servo-system, the

Frorn the Department of Anesthesiology, Tufts University School of Medicine and Pratt Clinc-New England Center Hospital, and the Behavior Research Laboratory of Harvard Medical School, Boston, Mass

This work was supported in part by grants from the National Institutes of Mental Health (M-3167), Unted States Public Health Service and from Merck, Sharp and Dohme Research Laboratories 


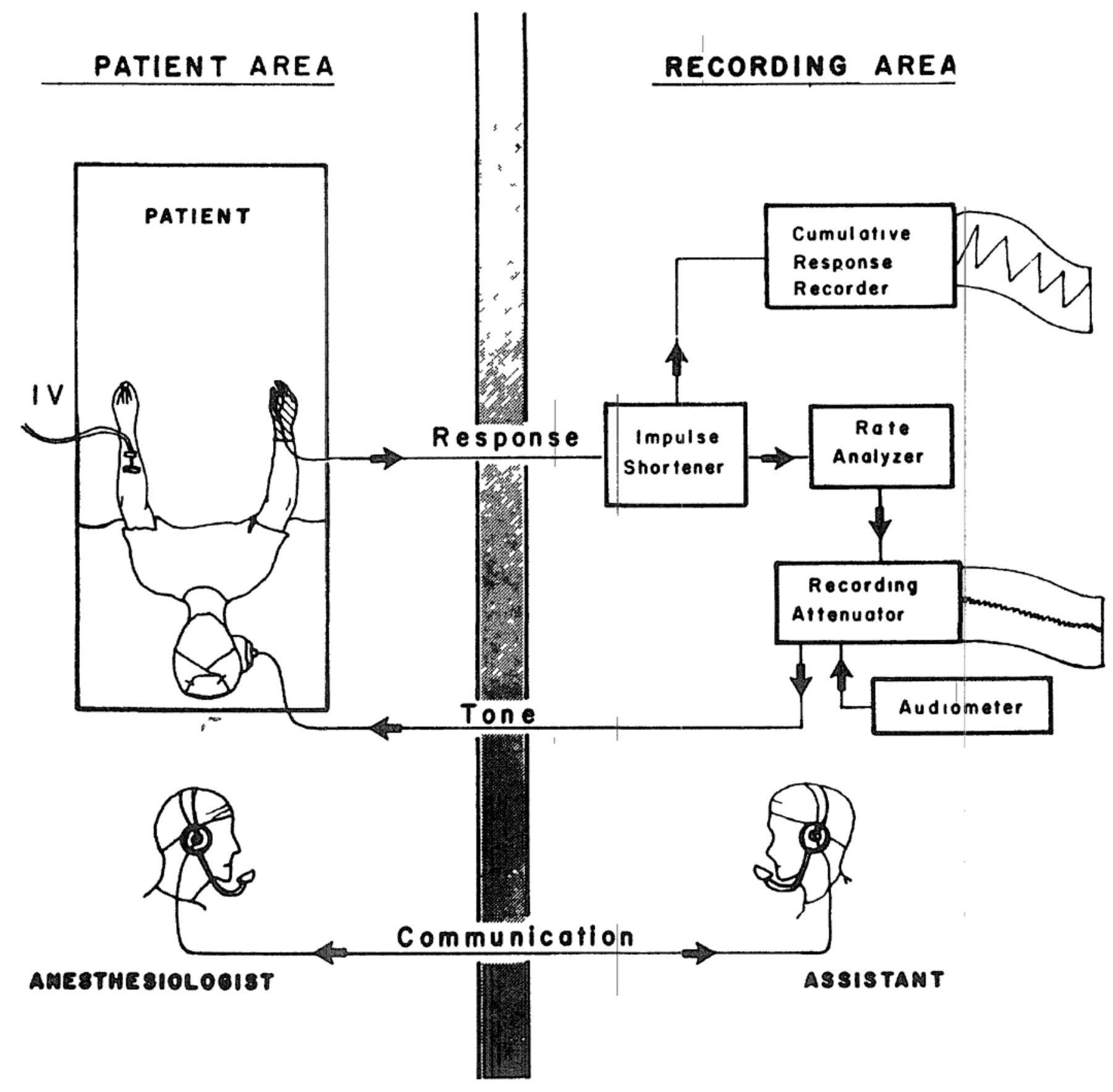

Figure 1 Schematic diagram of Free-Operant Behaviour Apparatus used for the study of amitriptyline

intensity of sound varies with the frequency of thumb and finger contact The rate of touching the thumb to the finger is recorded on paper and provides the primary response datum from the patient ( $F_{1 g} 2$ ) It was found to be objective and sensitive for any degree of sedation ${ }^{11-13}$

Each subject was brought to the anaesthesia area without medication one and one-half hours before the operation The control tracings of cumulative responses by means of the Free-Operant Behaviour Technique were run for 40 minutes. Following the initial observations, amitriptyline $(033 \mathrm{mg} / \mathrm{kg})$ was administered intravenously through a three-way stopcock connected to a venotube previously inserted in an antecubital vein In group I, the Free-Operant Behaviour was recorded for a penod of two hours after the administration of the drug and before induction of anaesthesia In group II the observations were carried out to three hours after cessation of anaesthesia In group III the blood pressure was contunuously recorded on a Sanborn recorder, using an intra-arterial polyethylene 
catheter connected to a Statham transducer (P23Db) The Ruva Roccl method was also employed and was read by the same experimenter on all patients

The heart rate was determined by means of either a Telecor pulse monitor or lead II of the electrocardıogram Mean arterial pressure was calculated by using the conventional formula

Control readings were taken for 30 munutes after the blood pressure and heart rate were allowed to stabilize Then amitriptyline $(033 \mathrm{mg} / \mathrm{kg}$ ) was administered untravenously, and the two parameters were monitored for 45 minutes.

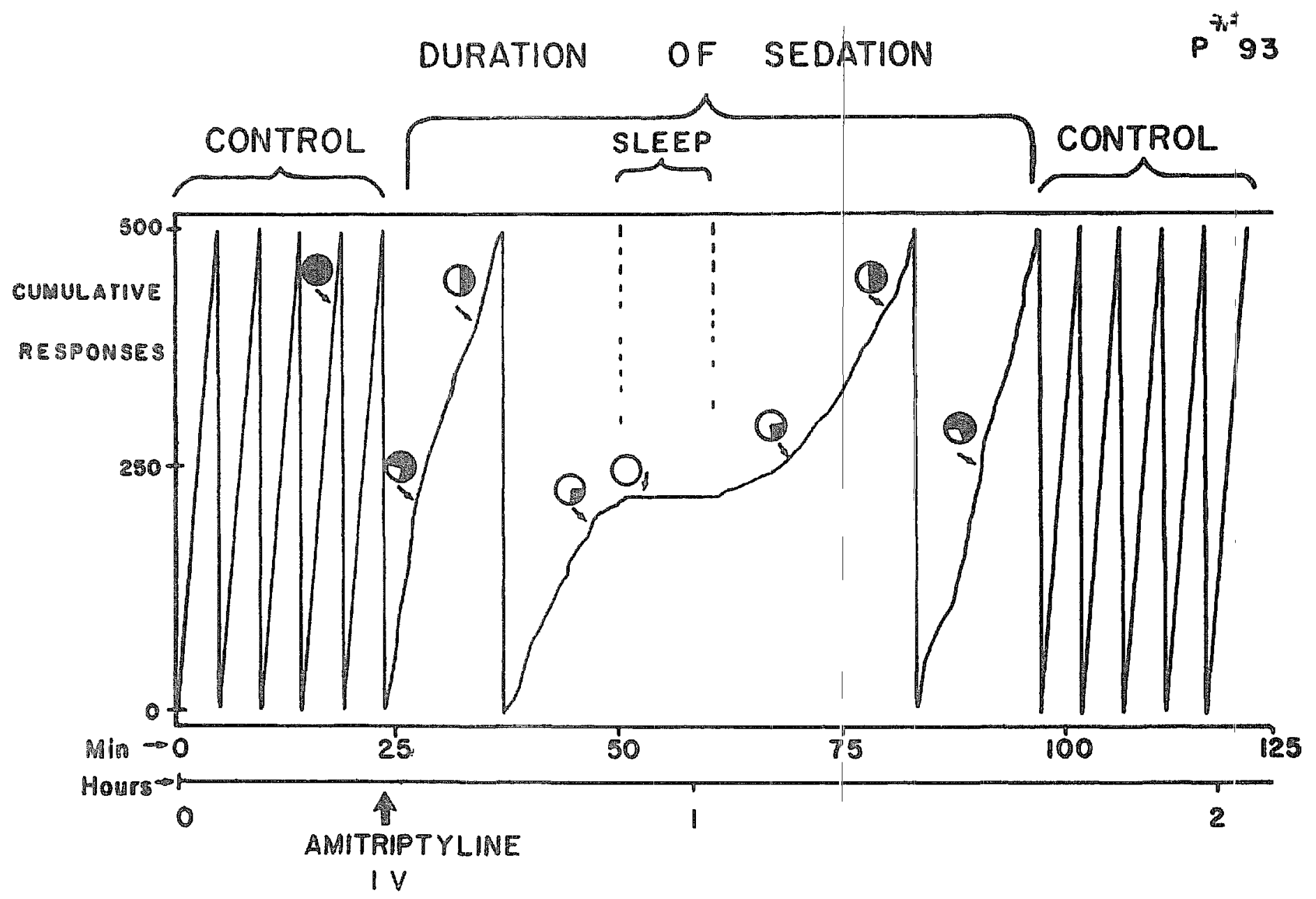

FiguRE 2 A cumulative response record (case 93) with a control rate of 110 responses per minute (indicated by filled carcle) Three minutes after injer tion of amitriptyline the response sate is reduced to three-quarters of the control rate as shown by the three-quarters filled circle, etc Twenty-five minutes after the injection of the drug, the rate is completely suppressed (sleep), as shown by the open crrcle Sedation is thown to last for 60 minutes and recovery takes place in a reverse pattern

\section{Results}

Group I Nine of the eleven patients showed a decrease in rate of response of the Free-Operant Behaviour after intravenous administration of amitriptyline The mean latency time was 35 minutes (range, 1 to 25 minutes), and the paltern of onset and recovery from sedation for each patient is shown in Figure 3 Eight patients reached the stage of complete suppression (sleep) in an average time of 28 minutes (range, 11 to 50 minutes) This period of complete suppression lasted for a mean ume of 10 minutes (range, 4 to 25 mmutes) Five patients were permitted to recover fully (as seen by the returm to control response rate) with 
mean time of 68 minutes (range, 38 to 99 minutes) Four patients recovered partially Two of the eleven patients showed no change in rate of response

Group II The mean Anaesthesia Administration Time (AAT) was 199 minutes (65 to 500 minutes) for the non-premedicated patients and 138 minutes (55 to 275 minutes) for those premedicated with ainitriptyline The duration of complete recovery (Anaesthesia Recovery Time Full-ARTF) was 65 minutes (5 to 156 minutes) for the non-premedicated patient, and 55 minutes (16 to 96 minutes) for those premedicated with amitriptyline

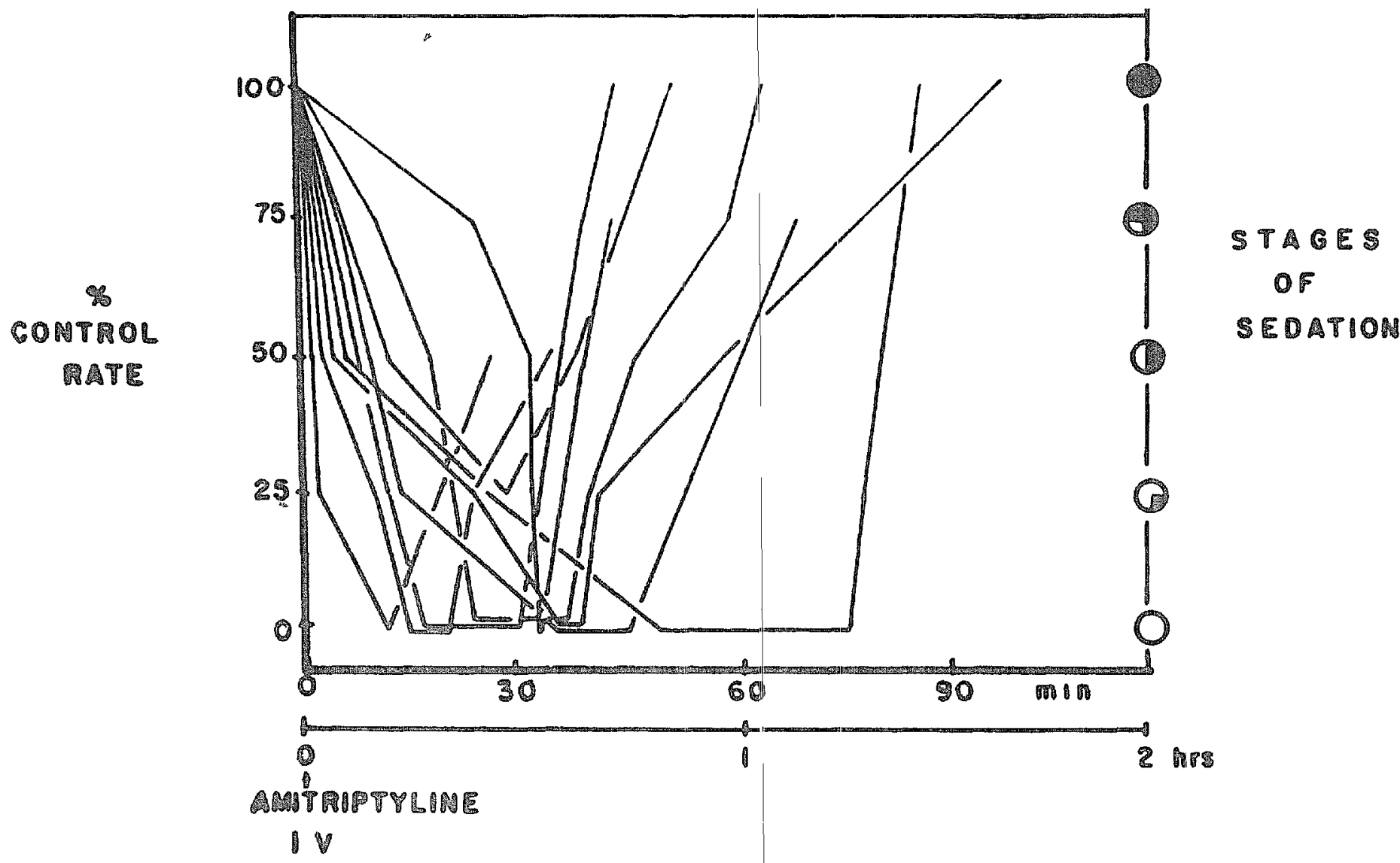

TMAE POS T-INAECTION

FIGURE 3 The degree of behaviour sedation following injection of amitrptyline (033 $\mathrm{mg} / \mathrm{kg}$ ) 1s shown by the percentage change of the control rate and identified by the open, partially closed, or closed circles and is plotted against time of change

TABLE H* $^{*}$

\begin{tabular}{lccccc}
\hline \hline & $\begin{array}{c}\text { Halothane without } \\
\text { piemedicant } \\
\text { (9 patients) }\end{array}$ & & \multicolumn{2}{c}{$\begin{array}{c}\text { Halothane } \\
\text { with amitriptyline } \\
\text { as a premedicant } \\
\text { (9 patients) }\end{array}$} \\
\cline { 2 - 3 } \cline { 5 - 6 } & Mean & Range & & Mean & Range \\
\hline AA & 199 & $65-500$ & & 138 & $55-275$ \\
ARTI & 19 & $1-68$ & 17 & $1-48$ \\
ARTQ & 27 & $2--75$ & 29 & $11-71$ \\
ARTH & 43 & $2-96$ & & 40 & $12-72$ \\
ARTF & 65 & $5-156$ & 55 & $16-96$ \\
TAT & 264 & $95-564$ & 179 & $71-332$ \\
\hline
\end{tabular}

*AAT = Anaesthesia administration time

ARTI = Anaesthesia recovery time, initial

ARTQ $=$ Anaesthesia recovery time, quarter

ARTH $=$ Anaesthesia recovery time, half

$\mathrm{ARTF}=$ Anaesthesia recovery time, full

$\mathrm{TAT}=$ Total anaesthesia time, 


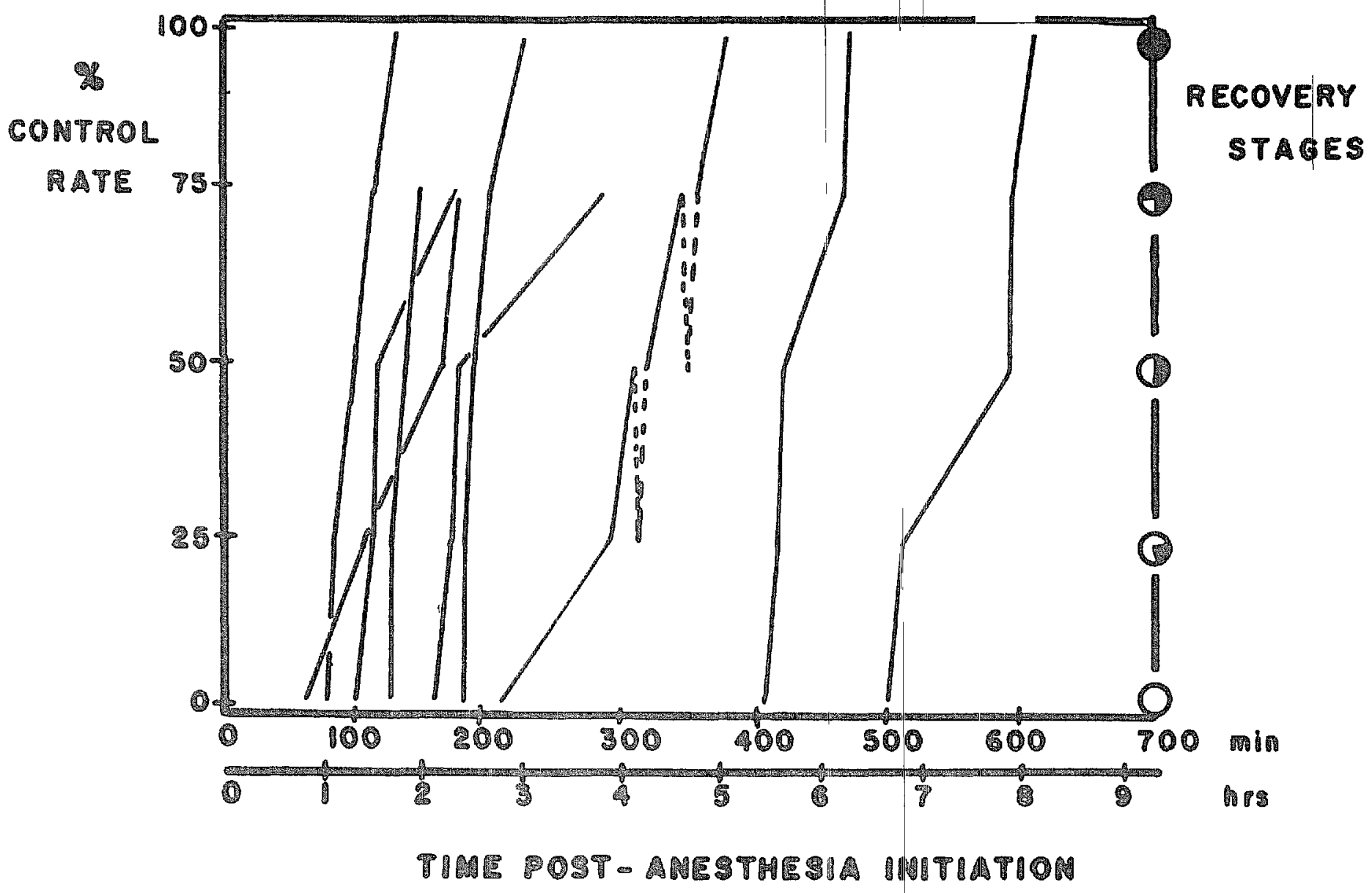

Figure 4 Post-anaesthesia recovery time and duration of recovery period following the adminstration of halothane anaesthesia without premedication plotted against percentage of control rate and stages of recovery (circles) One patient showed an episode of reanaesthetization (dotted line)

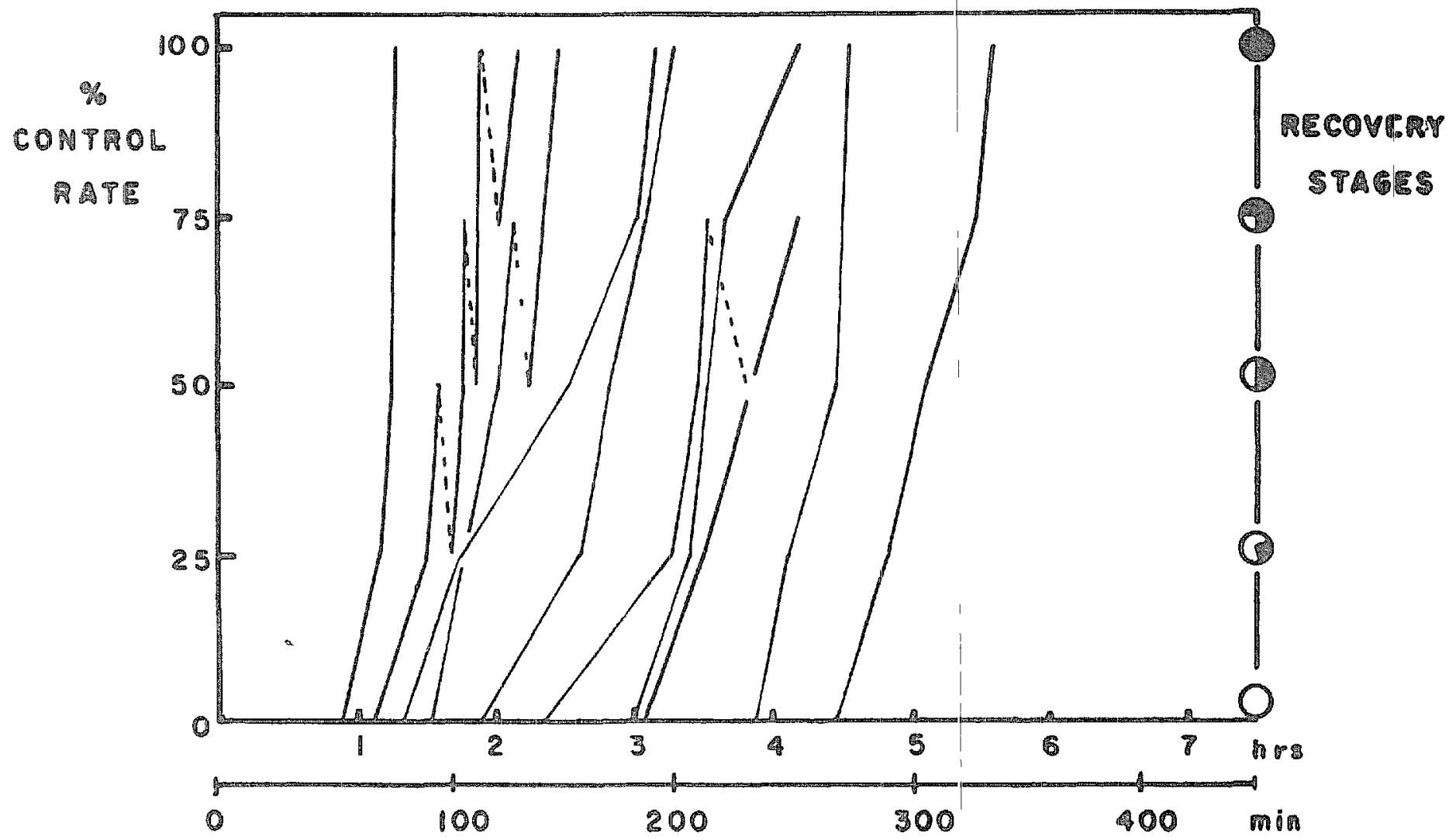

TIME - POST - ANESTHESIA INITIATION

Figure 5 Post-anaesthesia recovery tume and the duration of recovery period following amitriptyline and halothane anaesthesia plotted against the percentage of control rate and stages of recovery 
Figures 4 and 5 are the graphic representation of Free-Operant Behaviour Recovery of the two subdivisions of Group II, and Table I compares the results obtained on patients anaesthetized with halothane with and without amitriptyline premedication

Group III The mean systolic pressure was increased by $18 \pm 2 \mathrm{~mm}$. Hg (S D, \pm 66 , range, +5 to $+30 \mathrm{~mm} \mathrm{Hg}$ ) with average duration of 25 minutes The mean diastolic pressure increased by $10 \pm 27 \mathrm{~mm} \mathrm{Hg}$ (range, 0 to $25 \mathrm{~mm} \mathrm{Hg}$ ). The mean blood pressure was increased on the average by $13 \pm 2 \mathrm{~mm} \mathrm{Hg}$ (range, 2 to $27 \mathrm{~mm} \mathrm{Hg}$ ) The duration of increase in diastolic and mean pressure was comparable to the duration of increase in systolic pressure ( 23 and 25 minutes, respectively)

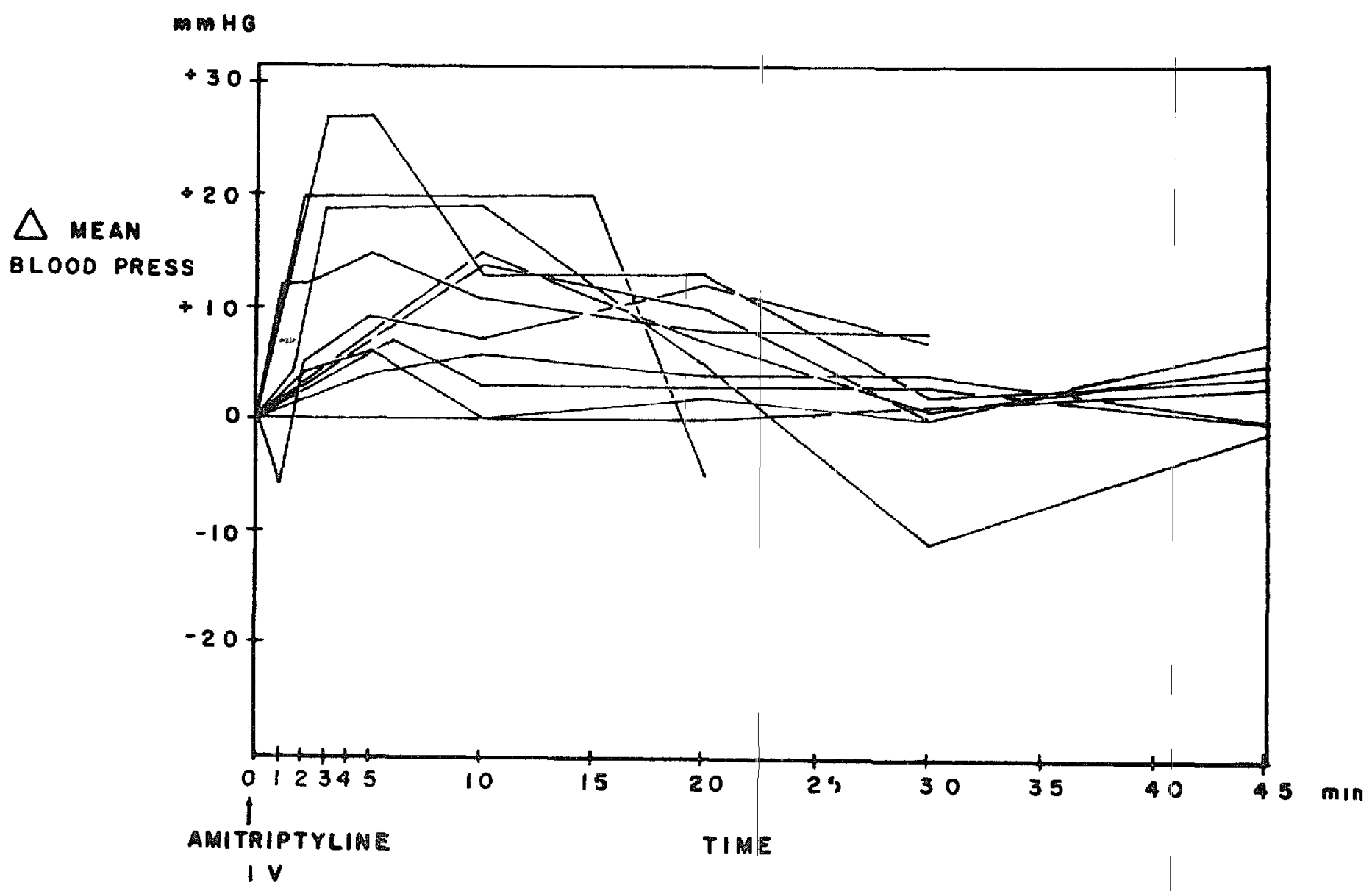

Figure 6 Changes in mean blood pressure for 11 patients after the admunistration of amitriptyline $(033 \mathrm{mg} / \mathrm{kg})$ intravenously

Figure 6 represents the changes in mean blood pressure in eleven patients following intravenous amitriptyline injections without anaesthesia The heart rate increased $6 \pm 2$ beats per minute, not a significant change

Side-effects Profuse pharyngolaryngeal secretions occurred during induction of anaesthesia or after tracheal intubation when arnitriptyline was given as a premedicant It became obvious that it exerted no antisialagogue activity and therefore it became necessary to admunister atropine immediately prior to anaesthesia

Nausea and vomiting occurred in one patient of the enture series.

\section{DisCUSSION}

One of the main purposes of pre-anaesthetic medication is to protect the patient aganst the so-called psychological trauma of undergoing surgery Other goals 
may vary from the production of sedation or analgesia, the relief of apprehension or anxiety, and the facilitation of induction of anaesthesia

Signs of apprehension may occur in patients who have received large doses of barbiturates, narcotics, or tranquillizers Sedation re'ulting in deep sleep before anaesthesia is usually associated with undesirable side-effects, $1 \mathrm{e}$, hypotension, respiratory depression, and nausea or emesis ${ }^{\mathbf{9}, 16}$

The Free-Operant Behaviour Technique (FOBT) described in this report has been shown to be extremely sensitive to explore the scale of sleep-arousal state in man ${ }^{11-13}$ After a control rate of response has been obtaned, any decrement of that rate is interpreted as sedation and any increment is interpreted as arousal.

If a comparison is made between clinical intermittent probing (painful stimulathon, talking to patient, etc) and the FOBT applied in this investigation the following facts emerge immediately The stumulation used to probe the state of a patient by the common clinical means is not callbrated in intensity and is intermittent in nature, whereas the FOBT uses a contmuous stimulation of constant and calubrated intensity The intermittent clinical probing, because of its intermitteni nature, cannot be applied without disturbirng the sleep-arousal state of the patient The Free-Operant Behaviour Technique uses a constant and conunuous stimulus and reflects the level of the sleep-arousal state as related to the control level It provides the opportunity of quantitating responses to analeptics An above-normal response rate is interpreted as an excitement state or abovearousal state This latter phenomenon has not been seen with amitriptyline

A double-blind study was believed to be unnecessary owing to the sensitivity of the FOBT method, and most of all because the patients were completely unaware that a drug was being administered to them Each patient served as his own control

The results obtamed with the FOBT provide evidence of the sedative effect of intravenously administered amitriptyline and that the same degree of sedation by means of an intramuscular injection requires a larger dose The mean anaesthesia recovery time was slightly shorter in patients premedicated with amitriptyline However, it cannot be concluded that this drug shortens the duration of recovery after halothane anaesthesia because the anaesthesia administration time was also shorter in the group of patients premedicaled with amitriptyline It has been shown previously that the duration of recovery from halothane is a function of the duration of admunistration ${ }^{11}$ and that amitriptyline does not alter the duration of recovery after halothane anaesthesia

The sedative action and the mild pressor effect of amitriptyline are functions that permit adequate preoperative sedation without circulatory depression Other significant effects are the mood-elevating properties which relieve apprehension In view of these effective functions, amitriptylune deserves further extensive clinical trial as a pre-anaesthetic agent

\section{SUMMARY}

Amitriptyline (Elavil) was evaluated as a premedicant sedative and its effect upon recovery tume following halothane anaesthesia was objectively quantitated 
In man by means of the Free-Operant Behaviour Technique Amitriptyline exerted a specific degree of sedation without prolonging recovery time following halothane anaesthesia Following the intravenous administration of amitriptyline, the arterial blood pressure either was slightly elevated or was maintained at the resting levels

\section{RÉSUnTÉ}

Amitriptylıne (Elavil) a été évalué pour son emploı comme médıcation préanesthésique, et son action sur le temps de recouvrement après anesthésie ${ }^{\prime a ̀}$ l'halothane a été objectivement mesuré chez l'homme au moyen de la technique de comportement-opérant-libre (Free-Operant Behaviour Technique) L'amitriptylıne produit une sédation quı ne fait aucun doute, sans pour cela prolonger le temps de recouvrement de l'halothane Sulvant l'administration intraveineuse d'amitriptyline, la pression artérielle était ou bien légèrement élevée ou était maintenue au niveau de control

\section{REFERENGES}

1 Arvazion, G H Amitriptyline in the Treatment of Depressive States Dis Nervous System 23936 (1962)

2 AYD, F J, JR Amitnptylne Therapy for Depressive Reactions Psychosomatics 146 (1960)

3 Toxicology of Antidepressants The First Hennemann Symposium on Psychosomatic Medicine, Chap 82 New York Lea and Febiger (1962)

4 Barsa, J A \& Saunders, J C Amitrptylne (Elavil)-A New Antdepressant Am J Psychiat 117939 (1961)

5 Bunt, C G, Gondon, W F, Holt, N F, \& Hondern, A Amitnptylune in Depressive States A Controlled Trial J Ment Sc1 108711 (1962)

6 Dorfman, W Clinical Expenences with Amitriptyline Psychosomatics 141 (1960)

7 Dunlop, E The Treatment of Depression in Private Practice Dis Nervous Systems, Suppl 22381 (1961)

8 Edelstern, E L Amitriptylune Therapy in Depressive States Combined with Anxiety Dis Nervous System 23931 (1962)

9 Etsten, B \& LI, T H Circulatory Effects of Chlorpromazine before and during Cyclopropane Anesthesia in Man Anesthesiology 18203 (1957)

10 Karabanow, O Amitnptyline in Depressive States Appl Therapeut 4838 (1962)

11 Lindsley, O R, HobiKa, J H, \& Etsten, B E Operant Behaviour during AnesthesiaA Contnuous and Objective Method Anesthesiology 22937 (1961)

12 LindsLex, O R Operant Behaviour durng Sleep-A Measure of Depth of Sleep Science 1263286 (1957)

13 Lindsley, $O \mathrm{R}$ \& ConRan, $P$ Operant Behaviour dunng EST-A Measure of Depth of Coma Dis Nervous System 23407 (1962)

14 Oltman, J A \& Friedman, S Elavil in the Treatment of Affective Disorders Am J Psychrat 118546 (1961)

15 Vaisberg, $M$ \& SaUnders, J C Amitriptylune in the Treatment of Depressive States Dis Nervous System 22546 (1961)

16 Viaud, $\mathrm{P}$ Les amines dénvées de la phénothrazine J Pharm \& Pharmacol (Pans) 6361 (1954)

17 Weiss, L B Clinical Use of Amitriptyline First Hennemann Symposium on Psychosomatic Medıcine, Chap 81 New York Lea and Febıger (1962) 